\title{
Relative influence of processes structuring fjord deep-water macrofaunal communities across multiple spatial scales
}

\author{
P. E. Brewin ${ }^{1,2, *}$, P. K. Probert ${ }^{1}$, M. F. Barker ${ }^{1}$ \\ ${ }^{1}$ Department of Marine Science, University of Otago, PO Box 56, Dunedin, New Zealand \\ ${ }^{2}$ Present address: Shallow Marine Surveys Group, Fisheries Department, PO Box 598, Stanley FIQQ 1ZZ, Falkland Islands
}

\begin{abstract}
We examined the processes that maintain spatially subdivided deep-basin macrobenthic communities in a New Zealand fjord. Based on previously reported quantitative taxa distribution data, we measured physical and biological processes acting at the sample scale (physical and nutritional sediment characteristics, predation), basin scale (disturbance, productivity, local connectivity) and the fjord scale (connectivity to the regional species pool). Using partial redundancy analysis (RDA), we partitioned their effects on community variability. Direct gradient analysis revealed that previously reported high-, medium- and low-diversity communities are similarly grouped according to their position along measured biotic and abiotic gradients, where $36 \%$ of community variation in niche space (i.e. after effects of distance along the fjord were removed) was explained by the full model. Variance partitioning showed that basin-scale factors explained the highest amount of variation in basin communities, followed by sample-scale and fjord-scale factors. Sample- and basin-scale factors were correlated. Examination of the residual component of community variation showed that further investigation into basin-scale processes is warranted. These data support the notion of multiscaled control of community dynamics. Fjords may be unique in representing an 'ecotone' type habitat demonstrating processes at similar scales to those maintaining shallow soft-sediment communities, and those of deep-sea systems. Furthermore, this analysis may understate the importance of connectivity to the regional species pool (fjord-scale process) in such habitats where local extinctions may be relatively frequent.
\end{abstract}

KEY WORDS: Macrofauna $\cdot$ Fjord $\cdot$ Spatial scale $\cdot$ Ecotone $\cdot$ Predation $\cdot$ Connectivity $\cdot$ Trophic Disturbance Resale or republication not permitted without written consent of the publisher

\section{INTRODUCTION}

Determining the processes driving community pattern is of key interest to ecologists. Characteristic of many communities is their spatial and temporal heterogeneity of pattern, where variability can be a function of exogenous (environmental) and/or endogenous (biological) processes. Such processes are thought to vary across multiple scales of space and time (Levin 1992), and are integrated in potentially non-linear ways (Sokal \& Oden 1978, Ricklefs 1987, Thrush et al. 2005). Progress in determining the processes driving community dynamics in the marine environment has been hindered by difficulties in defining poorly perceived spatial subdivision of biotic and abiotic factors (Swearer et al. 2002, Kinlan et al. 2005), and understanding their co-variance across scales (Garza 2008). Ultimately, the key to understanding the drivers of species diversity (the numbers of species and their distributions) lies in a better understanding of these highly integrated processes (Levin 1981, 1992, Thrush et al. 2000, Gaston 2003). In this respect, a multi-scale approach to the analysis of biotic and abiotic pattern has been shown to be particularly useful in both terrestrial and marine habitats (Ohmann \& Spies 1998, Williams et al. 2002, Thrush et al. 2005, Chapman \& Underwood 2008, Garza 2008). 
Fjord marine habitats are often classified as estuaries based on hydrography and geomorphology (Ketchum 1983, Burrell 1988). However, fjords may also be deep (often greater than $500 \mathrm{~m}$ water depth) and comparatively stable over time (Pickrill 1987, Syvitski et al. 1987), reflecting deeper offshore habitats (Grant 2000, Snelgrove \& Smith 2002). This suggests that community structure and related processes may span a broad range of spatial scales. Within shallow water soft-sediment communities, species pattern often shows strong spatial structure over scales of metres to 100s of metres (Thrush 1991), where biotic and abiotic processes acting over such scales are thought to be important in structuring local communities. Such processes may include microhabitat dynamics affecting interactions between individuals (e.g. Edgar \& Barrett 2002), water-driven mechanical and chemical sediment processes (e.g. Probert 1984, Guichard \& Bourget 1998), disturbance by benthic megafauna (e.g. Parry et al. 2003), and effects of 'ecosystem engineers' (e.g. Berkenbusch et al. 2000), to name a few. As spatial extent increases to $10 \mathrm{~s}$ of $\mathrm{km}$, processes related to a community's position on similarly scaled environmental gradients are evident (e.g. Morrisey et al. 1992a,b, Edgar \& Barrett 2002), being more relevant to species' larval distribution/colonisation dynamics (e.g. Snelgrove et al. 2001), and life history (Legendre et al. 1997). Recent studies have suggested that large- and small-scale processes may interact in non-linear ways (Coco et al. 2006), driving small-scale patterns directly or indirectly (Chapman \& Underwood 2008) in shallow softsediment communities.

The spatial and temporal scales of processes in deep-sea soft-sediment communities are thought to differ from those of shallow water communities. Small-scale patchiness is common among deep-sea communities, similar to shallow habitats (Tyler 1995, Levin et al. 2001, Gray 2002). However, spatial structure of such patch mosaics becomes evident over much larger (km) spatial scales (Grant 2000, Levin et al. 2001). This suggests that processes occurring over larger spatial scales may be more important for structuring local deep-sea communities compared to shallow communities; for example, surface productivity over latitudinal spatial scales (e.g. Glover et al. 2002), or effects of longterm historical processes (e.g. Wilson 1998). Thus, considering these 2 contrasting habitat types (shallow versus deep soft-sediment habitats), it is not clear where fjord deep communities lie on this continuum; determining the scales and interactions of processes maintaining fjord benthic communities will provide improved management strategies for these potentially unique ecosystems.

The Doubtful Sound complex in southwest New Zealand (Fig. 1) contains a network of deep basins that are spatially subdivided by shallow sills, giving rise to potentially strong spatial subdivision not seen in other marine systems. We employed a hierarchical approach to investigate processes maintaining deep-basin ben-

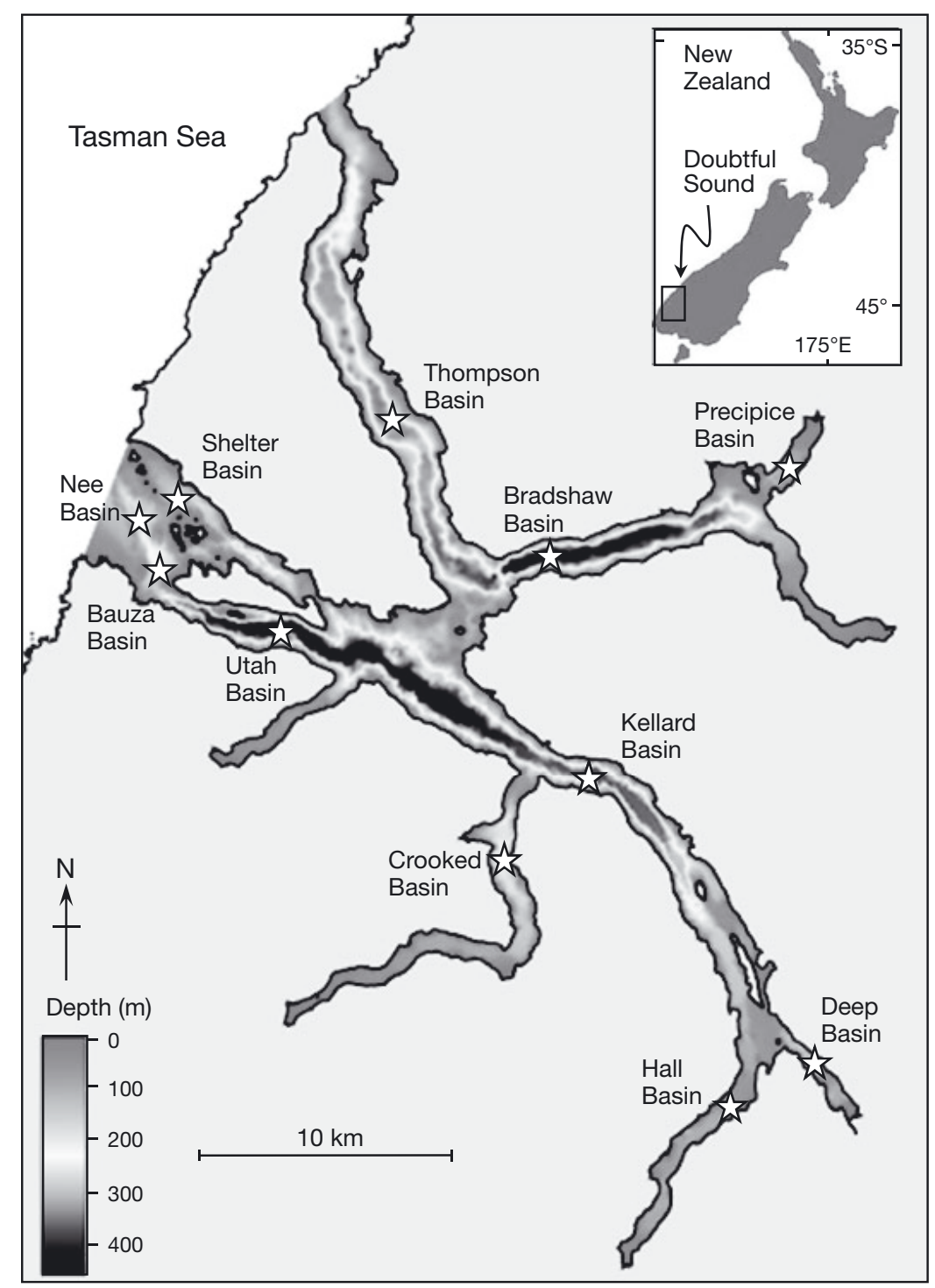

Fig. 1. Basin sites within Doubtful Sound, New Zealand 
thic community diversity. Brewin et al. (2008) quantitatively described the deep benthic macrofaunal communities in Doubtful Sound, showing that there was considerable patchiness in composition of taxa (identified to family or practical taxonomic level) and relative abundance (Shannon-Wiener diversity and Pielou evenness $)$ at the sample $\left(0.1 \mathrm{~m}^{2}\right)$ spatial scale throughout the fjord, similar to findings of early shallow-water fjord studies elsewhere (e.g. Angel \& Angel 1967, Rosenberg 1974, Gage \& Coghill 1977). However, despite this high level of patchiness, Brewin et al. (2008) reported significant between-basin variation in community alpha and beta diversity along the axes of Doubtful Sound. In the present study, we investigated those processes potentially maintaining such a community pattern. Previous authors have proposed a number of testable hypotheses explaining fjord-wide deep benthic community patterns in fjords around the globe. These include (1) the 'distance from species pool', which reflects spatial variability in fjord colonisation by species transported into the fjord, (2) the 'barrier hypothesis' that describes dispersal limitation by entrance sill depth, (3) the positive influence of sediment quality and grain-size heterogeneity on diversity and (4) the negative influence of high levels of organic carbon due to competitive exclusion by opportunist species (Amphipoda, Buhl-Jensen 1986, Buhl-Mortensen 1996; Crustacea, Buhl-Jensen \& Fosså 1991; Mollusca, BuhlMortensen \& Høisæter 1993; Foraminifera, KlitgaardKristensen \& Buhl-Mortensen 1999). The acceptance of each hypothesis tended to vary depending on taxa, reflecting different ecological tolerances.

In the present study, we aimed to better understand the ecological position of deep-fjord basin communities along the continuum of shallow to deep-water softsediment community dynamics by characterising them in terms of their multi-scaled community structuring processes. Using community data (identified to family or practical taxonomic unit) from Brewin et al. (2008), we examined spatial variability of deep-fjord communities using partial redundancy analysis (RDA; Legendre \& Legendre 1998) to partition the component significance of effects of physical and biological processes acting at the sample $(\mathrm{m})$, basin $(\mathrm{km})$ and fjord $(10 \mathrm{~s}$ of $\mathrm{km}$ ) spatial scales. Specifically, we examined the role of competition/predation, trophic interactions and physiological tolerance (sample scale); disturbance, productivity and local connectivity (basin scale); and connectivity to the regional species pool (fjord scale) in structuring community composition. This technique provides the correlation between explanatory matrices, and also the 'unexplained' fraction of variation in community structure. This was examined to gain insights into the nature of unexplained variation not accounted for in this study.

\section{MATERIALS AND METHODS}

Collection of biological and physical data. Biological sampling methodology and sample distribution within Doubtful Sound were described by Brewin et al. (2008) who concluded that Seymour Basin is not a true basin. It was therefore excluded in the present study, leaving 11 basins under current investigation (Fig. 1). Randomised samples within basins were taken using a $0.1 \mathrm{~m}^{2}$ Day grab. Numbers of samples per basin were approximately standardised over total area sampled in each basin, removing the effect of basin area on diversity. Fauna was extracted on a $0.5 \mathrm{~mm}$ sieve; and only the macrofaunal component of the community was analysed. All individuals were identified to family level or the closest practical taxonomic grouping to family (see Brewin et al. 2008 for details). Inventories and distribution/abundance analyses were reported by Brewin et al. (2008). Samples for sediment grain-size and chemical analyses were collected by sub-sampling biological grab samples with a hand-held core $(5 \mathrm{~cm}$ diameter, to a depth of $10 \mathrm{~cm}$ ), and immediately frozen. After thawing, samples were homogenised and split into thirds for sediment grain-size analysis, carbon and nitrogen analysis, and archiving. The gravel fraction $(\geq-1$ phi) was determined by wet sieving, the sand fraction by dry sieving using 5 whole phi sieves ( 0 to 4 phi), and the mud fraction ( 4 to 8 phi) by the pipette method (Lewis \& McConchie 1994). Percent sand, silt and clay were calculated; the gravel fraction was negligible in the majority of samples and was therefore omitted from the analysis. Median phi and sorting coefficient were calculated using a calculator for standard sedimentary statistics (RSA v.7.1, W. de Lange, University of Waikato). Sediments were dried and ground to a fine powder before analysis of total percent carbon and nitrogen (Carbo-Erba $1108 \mathrm{CHNS-O}$ elemental analyser to 7 decimal places), in conjunction with appropriate blanks.

Temperature and salinity data were measured in 9 out of 11 basins, and in an additional open-ocean site beyond the fjord entrance sill (Seabird SBE-19 CTD); CTD casts were not taken in Nee and Shelter Basins, as these are thought to be similar to Bauza Basin due to their close proximity at the entrance of Doubtful Sound (Fig. 1). A single cast was made in each basin approximately monthly between April 1999 and December 2000. Numbers of casts per site varied due to poor weather conditions and/or time constraints. When time/ weather permitted, additional casts were made between stations, although these were not used in numerical analyses (see below). CTD measurements were made throughout Doubtful Sound over an approximate $6 \mathrm{~h}$ period, providing what was thought to be a realistic snapshot of variability throughout the fjord. Raw CTD 
*.HEX files were processed using the standard SEASOFT (v.4.234) protocols and binned into $1 \mathrm{~m}$ depth intervals.

Biotic and abiotic explanatory factors and their rationale. A Venn diagram can be used to show the spatial components of variance partitioning in this study (after Anderson \& Gribble 1998; Fig. 2). We constructed 3 matrices of directly measured and derived explanatory variables that proxy those processes occurring at sample $\left(\mathrm{X}_{\mathrm{S}}\right)$, basin $\left(\mathrm{X}_{\mathrm{B}}\right)$ and fjord $\left(\mathrm{X}_{\mathrm{F}}\right)$ spatial scales. A summary of these variables is provided in Table 1. Selection of those factors was based on the flowing rational.

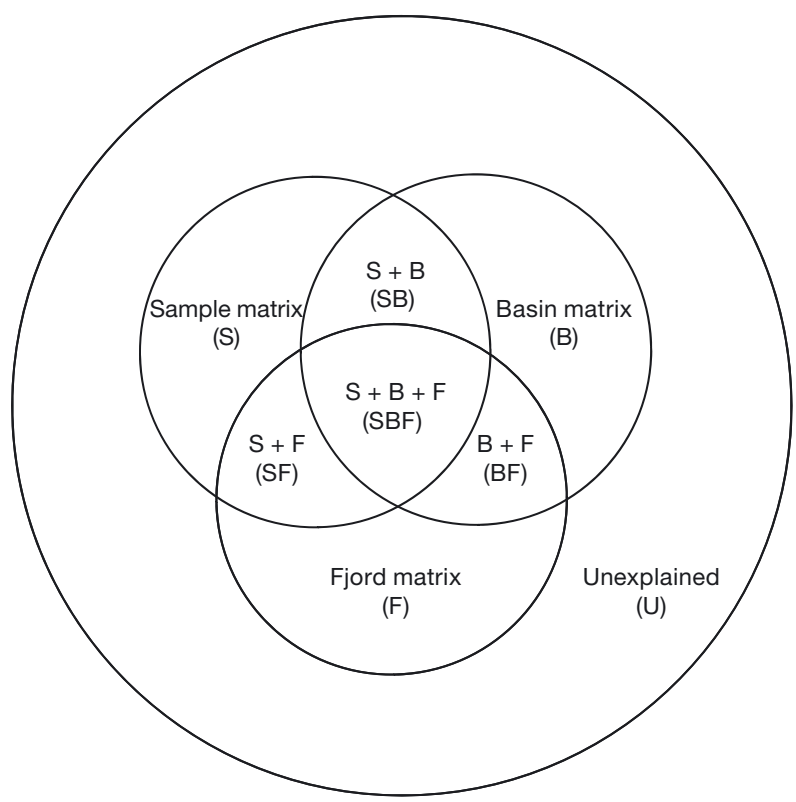

Fig. 2. Venn diagram (after Anderson \& Gribble 1998, modified for this study) of total variation in the species (Y) matrix, partitioned by environmental matrices (sample scale: $\mathrm{X}_{\mathrm{S}}$ basin scale: $\mathrm{X}_{\mathrm{B}}$ and fjord scale: $\mathrm{X}_{\mathrm{F}}$ ) into fractions of variance explained. Letters in brackets denote fractions calculated in the variance partitioning analysis
Sample-scale matrix: Proportion of predators: In shallow water soft-sediment communities, predators may have a negative effect on diversity due to their high abundance (Grant 2000). Conversely, in deep-sea communities, where predators are comparatively rare, there may be a positive response to community diversity due to reduction in competitive exclusion between detritivores. Here, the proportion of predators (\%) in each sample (PRED) was used to proxy those effects related to predation, and to test its effect on diversity. This is not strictly an independent variable, as predator data were extracted from the community data matrix. However, because PRED is not necessarily linearly related to the community data matrix, it can be used as an explanatory variable (P. Legendre pers. comm.) and interpreted ecologically. Taxa were designated as predators based on published accounts and taxonomist advice. Here taxa assigned as predators were the Eusiridae (Amphipoda), Cuspidariidae (Bivalvia), Buccinidae (Gastropoda), Nudibranchia, Anthuridae and Paranthuridae (Isopoda), Stomatopoda, Nemertea, and Aphroditidae, Dorvilleidae, Eunicidae, Euphrosinidae Glyceridae, Goniadidae, Hesionidae, Nephtyidae, Phyllodocidae and Sigalionidae (Polychaeta).

Sediment characteristics: The level of competitive interaction between individuals may be mediated by resource partitioning via sediment grain-size characteristics (MacArthur \& Levins 1967, Etter \& Grassle 1992). Percent sand, silt and clay, and median phi were measured. However, \% sand, \% clay and median phi were removed after statistical pre-screening (see below), leaving \% silt (SILT) remaining in the model. A sorting coefficient (SORT), which indicates the distribution of grain sizes in a sample, was calculated. Sediment nutritional quality may further proxy effects of competition between detritivores (Dauwe et al. 1998). New Zealand fjord basin sediments are rich in organic carbon, and well preserved in a highly reducing environment (Pickrill 1987). Percent carbon and nitrogen

Table 1. Summary of factors included in $\mathrm{X}_{\mathrm{S}}$ (sample), $\mathrm{X}_{\mathrm{B}}$ (basin) and $\mathrm{X}_{\mathrm{F}}$ (fjord-wide) matrices and the processes that were proxied. *indicates that residuals after regression with distance were used in the analyses

\begin{tabular}{|llll|}
\hline \multirow{2}{*}{ Spatial matrix } & Code & \multicolumn{1}{c|}{ Description } & \multicolumn{1}{c|}{ Process proxied } \\
\hline $\mathrm{X}_{\mathrm{S}}$ & PRED & Proportion of predators in each sample (\%) & Predator-mediated competitive interactions \\
& SILT & Proportion of silt in each sample (\%) & Trophic partitioning between detritivores \\
& SORT & Sorting coefficient of each sample & Trophic partitioning between detritivores \\
& $\mathrm{C}^{*}$ & Proportion of total carbon of each sample (\%) & Physiological stress from sediment anoxia \\
& $\mathrm{CN}$ & Carbon:nitrogen relationship (slope) & Nutritional quality of the sediment \\
$\mathrm{X}_{\mathrm{B}}$ & $\mathrm{SLOPE}$ & Slope of hills surrounding the basin $\left(^{\circ}\right)$ & Disturbance as related to large terrestrial inputs \\
& $\mathrm{SILL}^{*}$ & Local basin sill depth $(\mathrm{m})$ & Variability of basin anoxia \\
& $\mathrm{SI}^{*}$ & Surface stratification index & Variability in primary productivity \\
& $\mathrm{BC}_{\mathrm{F}}$ & Connectivity to adjacent basins & Between-basin variability in recruitment \\
& $\mathrm{CONN}^{*}$ & Fjord-wide variability in connectivity & Recruitment link to the regional species pool \\
\hline
\end{tabular}


were measured, and sediment quality was estimated using the slope of the carbon to nitrogen relationship $(\mathrm{CN})$. Because nitrogen is related to labile food sources, the slope indicates how much total carbon is related to nitrogen, where a relatively poor relationship indicates a predominance of refractory carbon (Parsons et al. 1984). New Zealand fjord sediments are low in inorganic carbon (Pickrill 1987). Therefore, excessive carbon content (being mostly refractory organic carbon) may reflect the degree to which sediments become anoxic. Percent carbon (C) was used here to proxy spatial variability in physiological tolerances of individuals to high organic carbon content.

Basin-scale matrix: Slip frequency: Ecological disturbance can be an important community structuring process (Buckling et al. 2000, McCabe \& Gotelli 2000), creating habitat patch mosaics at various stages of colonisation succession across landscapes. New Zealand fjord catchment areas are tectonically active, and the steep, densely vegetated fjord walls are subject to slope failures that vary spatially and temporally throughout the fjord. Large inputs of light, disaggregated muds and clays, including organic material, deposited by slips may disperse at basin-wide spatial scales (R. A. Pickrill unpubl. data). We defined slope failure as a basin-scale process of disturbance that occurs over long temporal scales. We measured the slope $\left(\mathrm{SLOPE},{ }^{\circ}\right)$ of the fjord wall surrounding each basin site. Slope of the hillside is a good predictor of slips in New Zealand fjords, where steep walls will have a higher slip frequency (approx. 1 in 150 yr) compared to shallow sloped walls (approx. 1 in 2000 yr; (R. A. Pickrill unpubl. data). SLOPE was calculated using the formula:

$$
\theta=\arctan (y / x) \times 180 / \pi
$$

where $\theta$ is the slope angle in degrees, $y=$ the vertical height $(\mathrm{m})$ of the highest peak adjacent to the basin, and $x=$ the horizontal distance $(\mathrm{m})$ from the slope peak to the shoreline. Measurements were taken from topographic charts of Doubtful Sound (Irwin \& Main 1981). Slope for the basin was calculated using the average of 4 equally spaced measurements from each side of the basin.

Sill depth: Typical of fjords world-wide (Farmer \& Freeland 1983), Doubtful Sound has strong fjord estuarine circulation, with a persistent low-salinity surface layer above saline, oceanic water (Stanton \& Pickard 1981). Because fjords are generally deep, surface waters remain highly structured throughout the fjord, and relatively stable over time compared to shallow estuaries where bottom-induced frictional forces cause continual mixing of upper layers. This well-structured surface layer and suppressed mixing with deeper water means that basin water can become statically isolated, resulting in periods of hypoxia or anoxia as a result of biological oxygen demand (Timothy \& Soon 2001). In Doubtful Sound, reduced oxygen levels were recorded down to $2.53 \mathrm{mg} \mathrm{l}^{-1}$ in Bradshaw Basin, $2.47 \mathrm{mg} \mathrm{l}^{-1}$ in Deep Basin, $1.02 \mathrm{mg} \mathrm{l}^{-1}$ in Hall Basin and $0.34 \mathrm{mg} \mathrm{l}^{-1}$ in Precipice Basin (P. Brewin unpubl. data, measured using standard Winkler protocols; coincident temperatures were approximately $12^{\circ} \mathrm{C}$ ). Anoxic or hypoxic events may have catastrophic effects on basin biota, and may also be species dependent (Diaz \& Rosenberg 1995). In the water column, reduced oxygen may have a unifying effect on the whole benthic community by completely overpowering any smaller-scale effects. Aure \& Stigebrandt (1989) demonstrated that rate of oxygen consumption increases linearly with decreasing sill depth in fjord silled basins. We used sill depth (SILL, m) as a proxy for the basin-wide effects of potential oxygen depletion or complete anoxia.

Primary productivity: Photosynthetically active radiation can be reduced to less than $1 \%$ at only $25 \mathrm{~m}$ depth in Doubtful Sound due to absorption by high concentrations of dissolved organic compounds (e.g. tannins, humic substances) in the surface low-salinity layer (Goebel et al. 2005). Due to strong horizontal gradients in the low-salinity layer, there are coincident gradients in the underwater light field, giving rise, in part, to strong horizontal gradients in pelagic primary productivity (Goebel et al. 2005). Gradients in primary productivity are reported to be major community structuring features in both shallow (e.g. Muylaert et al. 2000) and deep-sea soft-sediment habitats (e.g. Glover et al. 2001, 2002). Because the depth of all communities examined in the present study extends well beyond the detectable light levels (P. Brewin unpubl. Li-Cor spectro-radiometer measurements), deep-benthic communities are likely to be, in part, dependent on the phytodetrital rain for a carbon source. We used a surface stratification index (SI) to capture the long-term vertical structure of the upper $15 \mathrm{~m}$ water column. SI was calculated by the formula:

$$
\mathrm{SI}=\Delta S / \Delta Z
$$

where $\Delta S$ is the difference in salinity $(S)$ between the surface and $15 \mathrm{~m}$ depth, and $\Delta Z$ is the depth over which the difference in salinity was measured (i.e. $15 \mathrm{~m}$ ). SI was then averaged over the number of CTD samples. Because vertical mixing is related to increased productivity, and the inverse of mixing is stratification, high values of SI represent on average highly structured surface layers and are less likely to be productive. Thus, SI was used to proxy spatial and temporal variability in potential primary productivity above each basin.

Between-basin connectivity: Basin communities may be connected via density-driven water intrusions spilling over the sill (Burrell 1988, Gillibrand et al. 1995) from adjacent basins. This process may vary spatially 
and temporally throughout the fjord. Although intrusion events may be closely related to the processes regulating basin anoxia (see SILL, above), here intrusions are likely to be more frequent than anoxic or reduced oxygen events. Between-basin connectivity (BC) was captured by measuring the frequency of changes in bottom water temperature within each basin over time. Although water intrusion events are thought to be density driven, changes in bottom temperature give a clearer signal, as deep-water temperature is strongly correlated to density. Turnover within each basin was determined by calculating the change in average bottom water temperature (average temperature of water below the sill; $T$ ) between consecutive months $(t)$ throughout the study period at each site, i.e.:

$$
\Delta T=\left|T_{t}-T_{t+1}\right|
$$

The frequency distribution of $\Delta T \mathrm{~s}$ at each site was examined, and values of $\Delta T$ above the $25 \%$ quartile were considered to be ecologically significant changes. Finally, the number of significant $\Delta T$ s per site was divided by the number of casts per site. This means a high $\mathrm{BC}$ indicates a high intrusion rate and, therefore, is likely to be well connected to adjacent basins. As a consequence of this method, there is no error estimate for BC.

Fjord-scale matrix: Connectivity to the regional species pool: Local communities are maintained, in part, by connectivity to the regional species pool (MacArthur \& Wilson 1967, Loreau \& Mouquet 1999). In Doubtful Sound, offshore habitats are thought to be an historic and contemporary regional source of fjord species (Pickrill 1987, Knox 1980, Smith 2001, Brewin et al. 2008). Fjord estuarine circulation describes the inward flowing, mass-balance driven oceanic counter-current layer between by the highly stratified, seaward flowing low salinity surface layer and somewhat isolated basin waters (see SILL, above; Gibbs et al. 2000). This counter-current layer may act as a conduit by which larval propagules are transported into and throughout the fjord, and which may vary throughout the fjord via spatio-temporally variable meteorological (wind and rain) and tidal forcing (Gibbs et al. 2000). We captured the variability of the counter-current layer within each basin by calculating the average difference between mid-water salinity for each basin and that of the open ocean at coincident depths and sampling times; i.e. if basin and open-ocean water masses are similar, then they are likely to be well connected. Salinity $(S)$ was used for this analysis, as it is a highly conserved property of a water mass in the upper layers, giving the clearest signal. For each sampling incident, variability in connectivity (CONN) of each basin to the open ocean was calculated as:

$$
\mathrm{CONN}=\left(\Delta S_{\max }-\Delta S_{\min }\right)
$$

where at coincident depths between 20 and $100 \mathrm{~m}$ :

$$
\Delta S=\left|S_{\text {oceanic }}-S_{\text {basin }}\right|
$$

CONN for each basin was then averaged over all sampled months. A low CONN value indicates that the basin is relatively well connected to the open ocean (i.e. a low average difference between oceanic and basin mid-water salinity), and a high CONN value indicates that the basin is not well connected to the open ocean (i.e. a high average difference between oceanic and basin mid-water salinity). Therefore, CONN tests the role of connectivity to the regional species pool on local community diversity.

Data analysis. Community data were Hellinger transformed in order to apply equal weight to both rare and abundant species (Legendre \& Gallagher 2001). Probability plots of all explanatory variables were examined for normality; PRED was asin $(\sqrt{ } \mathrm{x})$ transformed as a result. Examination of Pearson's correlation matrix showed that SILT was negatively correlated with \% sand and median phi (-0.966 and -0.901 , respectively) resulting in their removal from analysis. Examination of variance inflation factors was done to reduce collinearity of variables (Ohmann \& Spies 1998, Muylaert et al. 2000), and backward elimination procedures were used to ensure the most parsimonious model while preserving interactions (Legendre \& Legendre 1998), resulting in \% clay being removed. Lastly, examination of linear correlations between distance from the fjord entrance and explanatory variables showed that a large proportion of variation in some variables was explained by distance. Considering that species' positions on a gradient will reflect similarity of environmental conditions, and not their position in physical space (Ardisson \& Bourget 1992), such spatial structure may act as a synthetic variable overlaying environmental pattern in space, leading to an overestimation of species-environment relationships (Borcard et al. 1992). Therefore, the spatial interaction was removed by detrending with respect to distance along the fjord in order to effectively isolate the pure effect of explanatory variables (Borcard et al. 1992, GithaigaMwicigi et al. 2002). Explanatory variables were detrended by linear regression (Legendre \& Legendre 1998) if distance explained more than $50 \%$ of the variation in that variable (Table 1). Consequently, the residuals of factors C, SILL, SI and CONN after regression against distance were used in the analysis.

Simple RDA was used for direct gradient analysis (arch effects were not detected in object ordinations after principal component analysis (PCA); Ter Braak \& Prentice 1988, Legendre \& Legendre 1998). Partial RDA was used to partition the variation in community matrix $(\mathrm{Y})$ explained by the 3 explanatory matrices 
containing variables that proxy processes acting at sample $\left(\mathrm{X}_{\mathrm{S}}\right)$, basin $\left(\mathrm{X}_{\mathrm{B}}\right)$ and fjord-wide scales $\left(\mathrm{X}_{\mathrm{F}}\right)$ (Table 1). The 'vegan' (v.1.17-3) library in $\mathrm{R}$ (v.2.11.1) was used for simple and partial RDA analyses, which includes the Peres-Neto et al. (2006) method for estimating unbiased explained variation $\left(\mathrm{R}^{2}\right)$. Shared fractions ( $\mathrm{SB}, \mathrm{BF}, \mathrm{SF}$, see Fig. 2) could not be tested as they are not independently calculated components of variation (Legendre \& Legendre 1998). In ecological data sets, it is common to have a large unexplained (fraction U) portion of variation (Ter Braak \& Prentice 1988, Ohmann \& Spies 1998). Therefore, PCA was done on the residual $\left(\mathrm{Y}_{\text {resid }}\right)$ matrix, and eigenvalues were mapped to explore the nature of unexplained variation (Borcard \& Legendre 1994).

\section{RESULTS}

\section{Sample-scale variables $\left(\mathbf{X}_{\mathrm{S}}\right)$}

Predatory taxa made up $8.3 \%$ of the total fauna collected. Highest proportions (\%) of PRED were found in the entrance basins (mean \pm SEM, Nee: $12.21 \pm 1.67$, Bauza: $12.18 \pm 4.99$, Shelter: $11.17 \pm 4.59$, Utah: $12.43 \pm$ 6.94; Table 2). Also notably high were proportions of predators in the 2 inner basins (Crooked: $12.36 \pm 23.99$, Precipice: $12.02 \pm 17.69$ ). In these basins, very high between-sample patchiness of predatory polychaetes has been reported (see Brewin et al. 2008 for taxonomic lists).

Sediment grain size varied between samples as well as between basins (Table 2). However, generally sediments from entrance basins (Bauza, Nee, Shelter) consisted of low SILT, i.e. a high percentage sand (percent silt and sand are negatively correlated, see 'Materials and methods: Data analysis'). Entrance basin sediments were well sorted with low mean SORT, suggesting that these basins are subject to wave action or current flow. Other basins generally had a higher SILT component (i.e. lower sand component); however, there was higher within-basin variability among inner basins. Sorting coefficients were higher than in entrance basins, suggesting a weaker current regime by comparison.

C was generally lowest in entrance basins (Bauza, Nee and Shelter Basins), and highest in inner fjord shallow basins (Crooked, Deep, Hall and Precipice Basins), despite wide variation between samples (Table 2). The relationship between \% carbon and distance from the fjord entrance gave an $\mathrm{r}^{2}=0.62(\mathrm{n}=$ 157); therefore, the variable used in subsequent analyses is the residual of $\mathrm{C}$ versus distance. Percentage nitrogen followed a similar pattern. However, at entrance basins, nitrogen was often below detectable levels. The quality of sedimentary carbon as a food

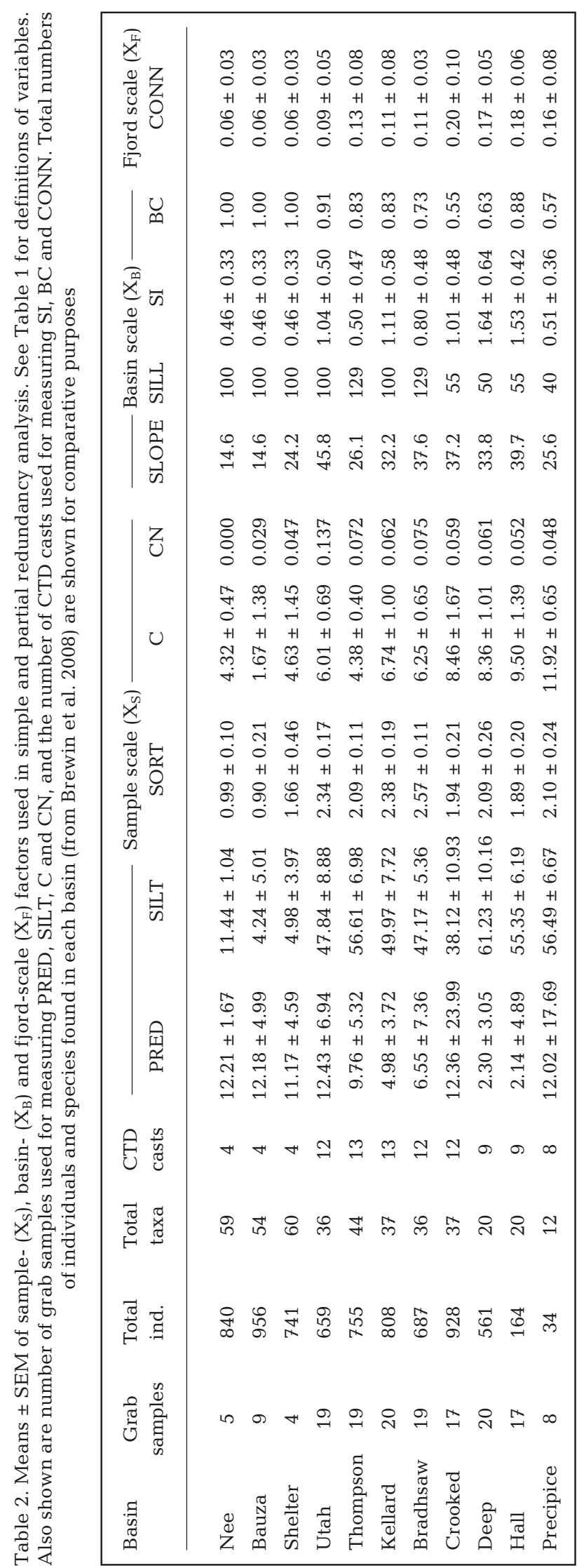


source varied between basins as reflected by the value of $\mathrm{CN}$. Entrance basins and Precipice Basin had the lowest carbon to nitrogen relationship, suggesting that an excess of refractory carbon was present, and therefore sediments were nutritionally of low quality. CN values for Crooked, Deep, Hall and Kellard Basins were slightly higher, suggesting nutritionally better quality sediment. Highest $\mathrm{CN}$ values and, therefore, highest quality sediments were found in Bradshaw, Thompson and Utah Basins.

\section{Basin-wide variables $\left(\mathrm{X}_{\mathrm{B}}\right)$}

SLOPE surrounding each basin varied between the steepest slope in Utah Basin $\left(45.8^{\circ}\right)$ to the shallowest slope on the islands around the entrance basins (Bauza, Nee: $14.6^{\circ}$, Shelter: $24.2^{\circ}$; Table 2). By comparing this to Pickrill's unpublished results, our data suggest that the occurrence of slips is highest in Utah Basin (about 1 in $200 \mathrm{yr}$ ), and least frequent at the entrance (1 in $2000 \mathrm{yr}$ ). The frequency of slips in most basins is greater than 1 in 500 yr.

Between-basin variability in probability of anoxia was proxied by SILL. Entrance basins and main channel basins had the deepest sill ( $\geq 100 \mathrm{~m}$ depth), while inner-most fjord basins and Crooked Basin had the shallowest sills (approximately $50 \mathrm{~m}$ depth; Table 2). The relationship between sill depth and distance from the entrance of the fjord gave an $r^{2}=0.51(n=157)$. Therefore, the residuals of SILL versus distance were used in the analysis to remove the effect of gradients in sill-forming geological processes that may mask the effect of SILL on the basin community.

Spatial and temporal variation in the SI of the upper $15 \mathrm{~m}$ water layer varied spatially and temporally throughout Doubtful Sound (Table 2). The lowest mean SI was found at the entrance of Doubtful Sound (Bauza, Shelter, Nee Basins), and an equally low standard deviation $(0.46 \pm 0.33)$ suggests that low stratification is consistent over time. Mean SI in Bradshaw and Thompson Basins was also low $(0.80 \pm 0.48$ and $0.50 \pm$ 0.47 , respectively), although temporally they were more variable. Deep and Hall Basins showed highest mean SI (1.64 \pm 0.64 and $1.53 \pm 0.42$, respectively). SI was correlated to distance from the fjord entrance $\left(\mathrm{r}^{2}=\right.$ $0.60, \mathrm{n}=157$ ); therefore, the residuals of SI versus distance were used in the analysis.

BC varied spatially throughout Doubtful Sound (Table 2), and intrusion events were confirmed by examination of contour plots (not shown here). Generally, entrance basins had a high frequency of intrusions, being well connected to adjacent basins, while inner-most basins (Deep, Precipice and Crooked Basins) had on average fewer deep-water intrusions, and are therefore less well connected to adjacent basins (Table 2). Hall Basin (an inner fjord basin) showed unusually high $\mathrm{BC}$ compared to others, being more comparable to mid-fjord basins.

\section{Fjord-wide variables $\left(\mathrm{X}_{\mathrm{F}}\right)$}

Spatial and temporal variation in connectivity of basins to the entrance of Doubtful Sound is captured by CONN. Here, the portion of the water column of interest is between approximately 20 and $100 \mathrm{~m}$ depth, i.e. the zone of the oceanic counter-current layer (see 'Materials and methods: Fjord-scale matrix'). The along-fjord salinity contoured profiles for April 1999 and July 2000 are shown in Fig. 3 as examples of spatial and temporal variability of salinity in the countercurrent layer. Note that the depth of the 35 psu isohaline varies temporally and spatially throughout the fjord. In April 1999, the 35 psu isohaline was depressed to a depth below that of the Deep Basin entrance sill, suggesting that Deep Basin was possibly not well connected to the open coast at that time. Conversely, the 35 psu isohaline was above the sill depth in July 2000, suggesting that at that time Deep Basin was possibly better connected to the open ocean via the oceanic counter-current layer. Entrance basins were generally well connected with the open ocean, although some variability in this region was detected. Inner-most basins (Crooked, Hall, Deep, Precipice Basins) were generally poorly connected to the open ocean, although variability in Crooked Basin was particularly high (Table 2). Connectivity was related to distance $\left(\mathrm{r}^{2}=0.71, \mathrm{n}=157\right)$, therefore CONN versus distance residuals were used in the analysis.

\section{Direct gradient analysis}

Results of simple gradient analysis are shown in Table 3 . The total variation in the community matrix explained by all environmental variables was $36.17 \%$. The first and second canonical axes explained $61.58 \%$ (axis I $=34.9 \%$, axis II $=26.6 \%$ ) of community variation constrained by all environmental variables. A tri-plot depicting the positions of basins and taxa along environmental gradients in 2D ordination space is shown in Fig. 4. The main gradients associated with axis I are variations in the PRED and BC (negative direction), and high SILT and SLOPE (positive direction). Axis II represents a gradient of low to high CONN and C. The positions of basins along these gradients are implied in this plot, showing that Bauza, Nee and Shelter Basins are well connected to each other and contain high proportions of predators compared to Deep Basin at the 


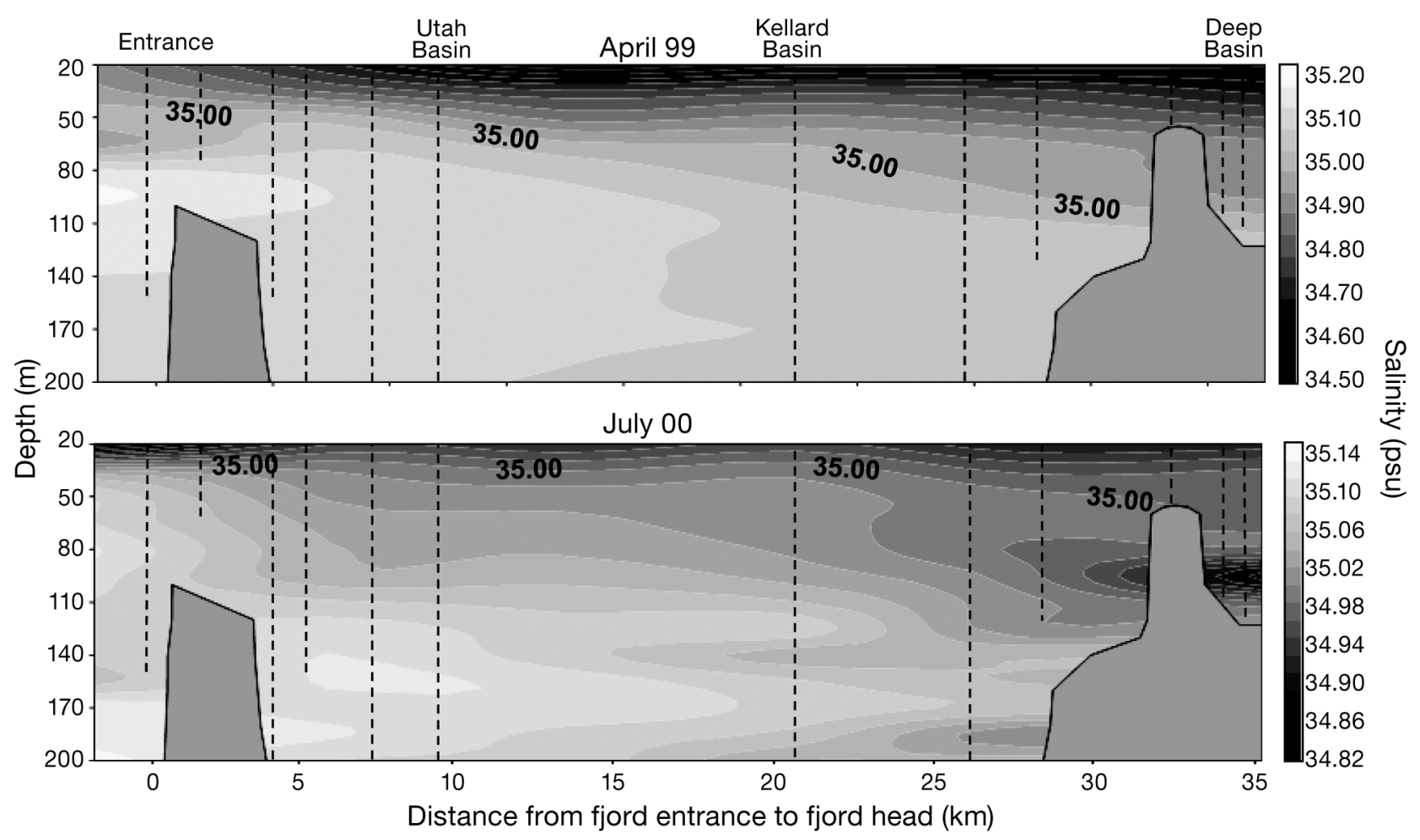

Fig. 3. Examples of spatial and temporal variability in along-fjord (west-east) vertical salinity stratification between 20 and $200 \mathrm{~m}$ depth for April 1999 and July 2000. The 35.00 psu isohaline is highlighted for reference purposes. Note differences in psu scales between plots. Vertical dashed lines depict locations of CTD casts. Also shown is the approximate bottom topography of the fjord entrance sill and Deep Basin entrance sill (outlined grey blocks)

Table 3. Results of the simple redundancy analysis between the community matrix (Hellinger transformed) and an environmental matrix of all environmental variables combined. Non-canonical axes not shown. PCA: principal component analysis

Total inertia $(\mathrm{PCA})=99.83003$, total variance $(\mathrm{PCA})=0.63994$

percentage of the total variance of $\mathrm{Y}$ accounted for $(\mathrm{PCA})=36.17544$.

Canonical analysis:

total inertia $=36.11274$, total sum of canonical eigenvalues $=0.2314$

\begin{tabular}{|c|c|c|c|c|c|c|c|c|c|}
\hline I & II & III & IV & $\mathrm{V}$ & VI & VII & VIII & IX & $\mathrm{X}$ \\
\hline \multicolumn{10}{|c|}{ Percentage of total variance of PCA } \\
\hline 12.64 & 9.64 & 4.56 & 3.13 & 2.38 & 1.67 & 0.83 & 0.65 & 0.43 & 0.26 \\
\hline \multicolumn{10}{|c|}{ Cumulative percentage of total variance of PCA } \\
\hline 12.64 & 22.28 & 26.84 & 29.96 & 32.34 & 34.01 & 34.83 & 35.49 & 35.92 & 36.17 \\
\hline \multicolumn{10}{|c|}{ Canonical eigenvalues } \\
\hline 0.08088 & 0.06167 & 0.02918 & 0.02001 & 0.01521 & 0.01067 & 0.00529 & 0.00419 & 0.00275 & 0.00164 \\
\hline \multicolumn{10}{|c|}{ Cumulative percentage of canonical variance } \\
\hline 34.94 & 61.58 & 74.19 & 82.83 & 89.40 & 94.01 & 96.30 & 98.11 & 99.29 & 100.00 \\
\hline
\end{tabular}

other end of this gradient, where Deep Basin was characterised by high SILT and relatively steep sloping walls. Along axis II, Precipice and Crooked Basins were related to highly variable connectivity to the open ocean and high carbon content of the sediments, while Bradshaw Basin was positioned at the other end of this gradient.
The relative position of taxa along environmental gradients can also be inferred. In this representation, a perpendicular line can be drawn from the position of the taxa to the environmental vector, indicating the position of the taxon on that gradient, and can be considered to be a measure of environmental tolerance. For plot clarity, the first 30 important taxa are shown in 


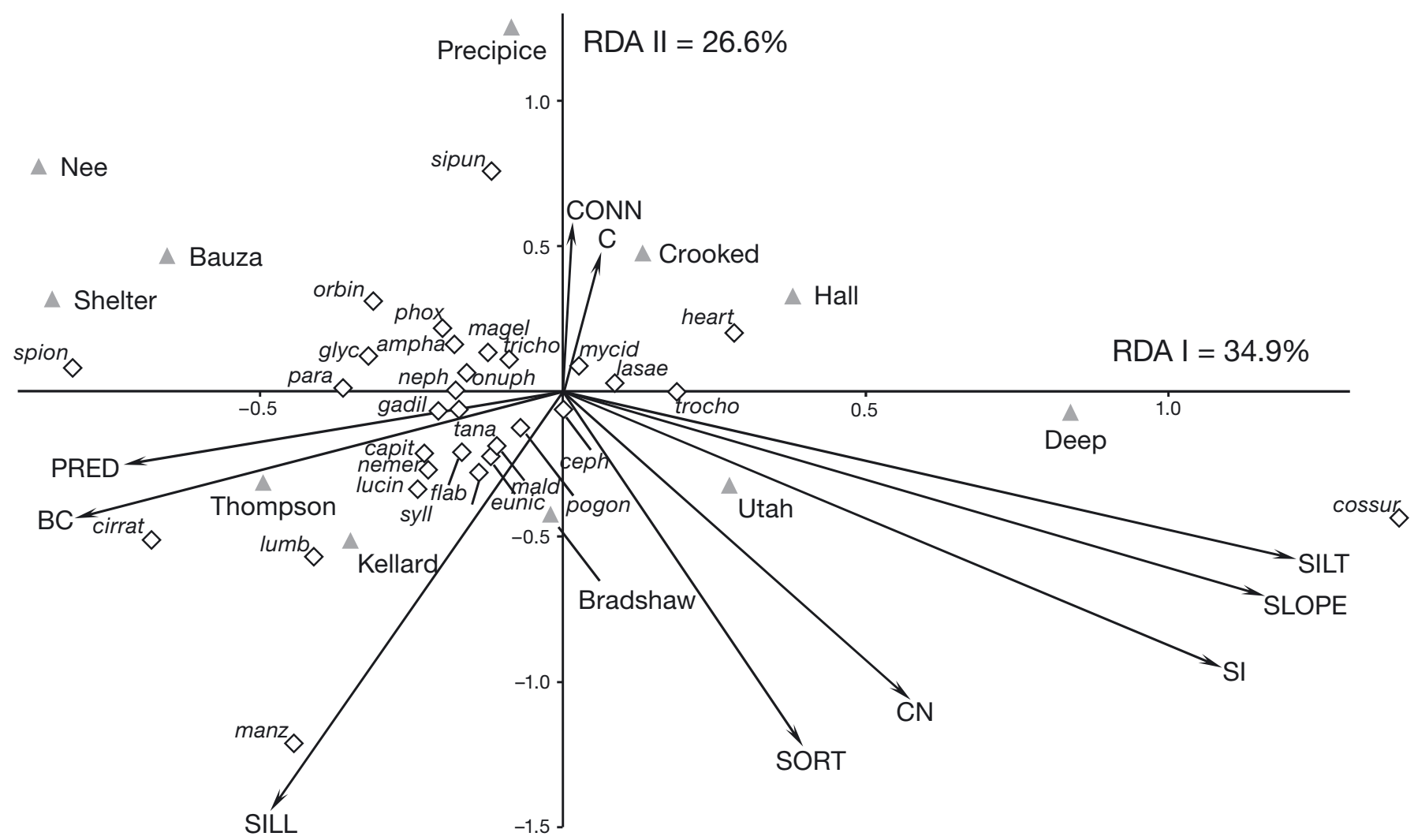

Fig. 4. Redundancy analysis (RDA) ordination tri-plot of the first 2 canonical axes showing site centroids (filled triangles), environmental variables (arrows), and taxa (open diamonds). Environmental values and taxa values were equally scaled. For plot clarity, the first 30 taxa explaining the most variation in the 2 axes are shown. See Table 1 for variable names. Key to taxa abbreviations: nemer $=$ Nemertea, syll $=$ Syllidae, neph $=$ Nephtyidae, glyc $=$ Glyceridae, eunic $=$ Eunicidae, lumb $=$ Lumbrineridae, onuph $=$ Onuphidae, spion $=$ Spionidae, magel $=$ Magelonidae, cirrat $=$ Cirratulidae, trocho $=$ Trochochaetidae, orbin $=$ Orbiniidae, para $=$ Paraonidae, cossur $=$ Cossuridae , capit $=$ Capitellidae, mald $=$ Maldanidae, fla $b=$ Flabelligeridae, ampha $=$ Ampharetidae, tricho $=$ Trichobranchidae, $\operatorname{manz}=$ Manzanellidae, lucin $=$ Lucinidae, lasae $=$ Lasaeidae, gadil $=$ Gadilidae,$c e p h=$ Cephalocarida, mycid $=$ Mysidacea, tana $=$ Tanaidacea, phox $=$ Phoxocephalidae, pogon = Pogonophora, sipun = Sipuncula, heart = Echinoidea

Fig. 4, and some key examples are noted here. The polychaete families Spionidae (suspension and/or surface deposit feeders) and Cirratulidae (surface-deposit feeders) are closely related to high proportions of predators (Bauza, Nee, Shelter, Utah). Of the taxa describing those basins, 3 predatory taxa explained significant amounts of variance (Glyceridae, Nephtyidae, Nemertea). The positions of the Manzanellidae, Lucinidae (bivalves) and Pogonophora are of interest because they harbour chemoautotrophic bacteria (Brewin et al. 2008). These were related to Thompson and Kellard Basins and the positive gradients of between-basin connectivity and sill depth, and negative gradients of variable connectivity to the open ocean and \% carbon in the sediments. The position of the Cossuridae (surface deposit feeding polychaetes) was related to innermost basins (Deep and Hall), and placed along gradients of high silt content of the sediments, steeply sloping fjord walls and high surface stratification. The Sipuncula were positioned along the positive gradient of high carbon in sediments, and highly variable connectivity to the open ocean, particularly in Precipice Basin.

\section{Partitioning of variability}

The partitioned (adjusted) variance of the community matrix $(\mathrm{Y})$ by the 3 matrices of explanatory variables is shown in Table 4 . Total variation explained by all variables $(36.17 \%)$ was significant $(p=0.001)$. The variance explained solely by sample-scale variables $\left(\mathrm{X}_{\mathrm{S}}\right)$ was $8.64 \%$, which was lower than the variation explained by basin-scale factors $\left(\mathrm{X}_{\mathrm{B}}\right.$ : $\left.12.71 \%\right)$, but larger than that explained by the fjord-scale factors $\left(X_{F}: 2.71 \%\right)$. Explained variation for each matrix was significant $(p=0.001)$ after 200 permutations. Because the degrees of freedom (df1) are equal to the number of variables in each matrix, it can be said that basinand fjord-scale variables explained more than sample- 
Table 4. Results of partial redundancy analysis between the community matrix (Hellinger transformed) and 3 environmental matrices (sample, basin and fjord scales). Fractions are those shown in the Venn diagram (Fig. 2). * Significant after 999 permutations under the reduced model. PCA: principal component analysis

\begin{tabular}{|c|c|c|c|c|c|c|c|}
\hline \multicolumn{3}{|c|}{$\begin{array}{l}\text { Total inertia }(\mathrm{PCA})=99.82993 \\
\text { total sum of canonical eigenvalues }=0.23149 \text {, }\end{array}$} & \multirow{2}{*}{$\frac{\mathrm{df1}}{10}$} & \multirow{2}{*}{$\frac{\mathrm{df} 2}{146}$} & $F$ & $\mathrm{p}$ & \multirow[b]{3}{*}{$\begin{array}{l}\text { Variance explained } \\
\text { per variable }\end{array}$} \\
\hline \multicolumn{3}{|c|}{ Total explained variation $=0.36175$} & & & 8.27477 & 0.001 & \\
\hline Fraction & $\begin{array}{l}\text { Sum of canonical } \\
\text { eigenvalues }\end{array}$ & $\begin{array}{l}\text { Explained variation } \\
\quad\left(\text { adjusted } R^{2} \text { ) }\right.\end{array}$ & df1 & df2 & $F$ & $\mathrm{p}$ & \\
\hline S & 0.024593 & 0.08636 & 5 & 146 & 4.83 & $0.001^{*}$ & 0.01727 \\
\hline B & 0.032522 & 0.12714 & 4 & 146 & 8.05 & $0.001^{*}$ & 0.03179 \\
\hline F & 0.007000 & 0.02709 & 1 & 146 & 6.85 & $0.001^{*}$ & 0.02709 \\
\hline SB & 0.018679 & 0.07885 & 0 & & Cannot be tested & & \\
\hline $\mathrm{BF}$ & -0.000262 & -0.00221 & 0 & & Cannot be tested & & \\
\hline $\mathrm{SF}$ & 0.001519 & 0.00783 & 0 & & Cannot be tested & & \\
\hline SBF & -0.000313 & -0.00570 & 0 & & Cannot be tested & & \\
\hline $\mathrm{U}$ & 0.147751 & 0.68063 & & & & & \\
\hline
\end{tabular}

scale variables on a per-variable basis (Table 4). Worth noting are the correlations between each matrix of variables. The correlation between sample- and basinscale variables (fraction $\mathrm{SB}_{\text {; }}$ see Fig. 2 ) $=7.89 \%$, suggesting some correlation between the 2 sets of variables. The low variation explained by fractions BF $(-0.2 \%)$ and SF $(0.8 \%)$ suggests that the fjord-scale variable CONN is close to completely independent of interactions between other explanatory variables. The negative value for fraction SBF (variance shared by all matrices) suggests that the fit for the whole model explains variation in the community matrix slightly better than the sum of the individual effects. This may be due to 1 or more explanatory variables having effects of the opposite sign to the $y$ variables (Legendre \& Legendre 1998). The residual fraction (U: unexplained variation) is $68.06 \%$.

\section{Analysis of residual matrix}

The matrix of unexplained variation $\left(\mathrm{Y}_{\text {res }}\right)$ was analysed using PCA. This analysis helps determine potential factors that explained variation in the community matrix. The first 2 principal axes explained $26.61 \%$ of the variation in the community residual matrix, and
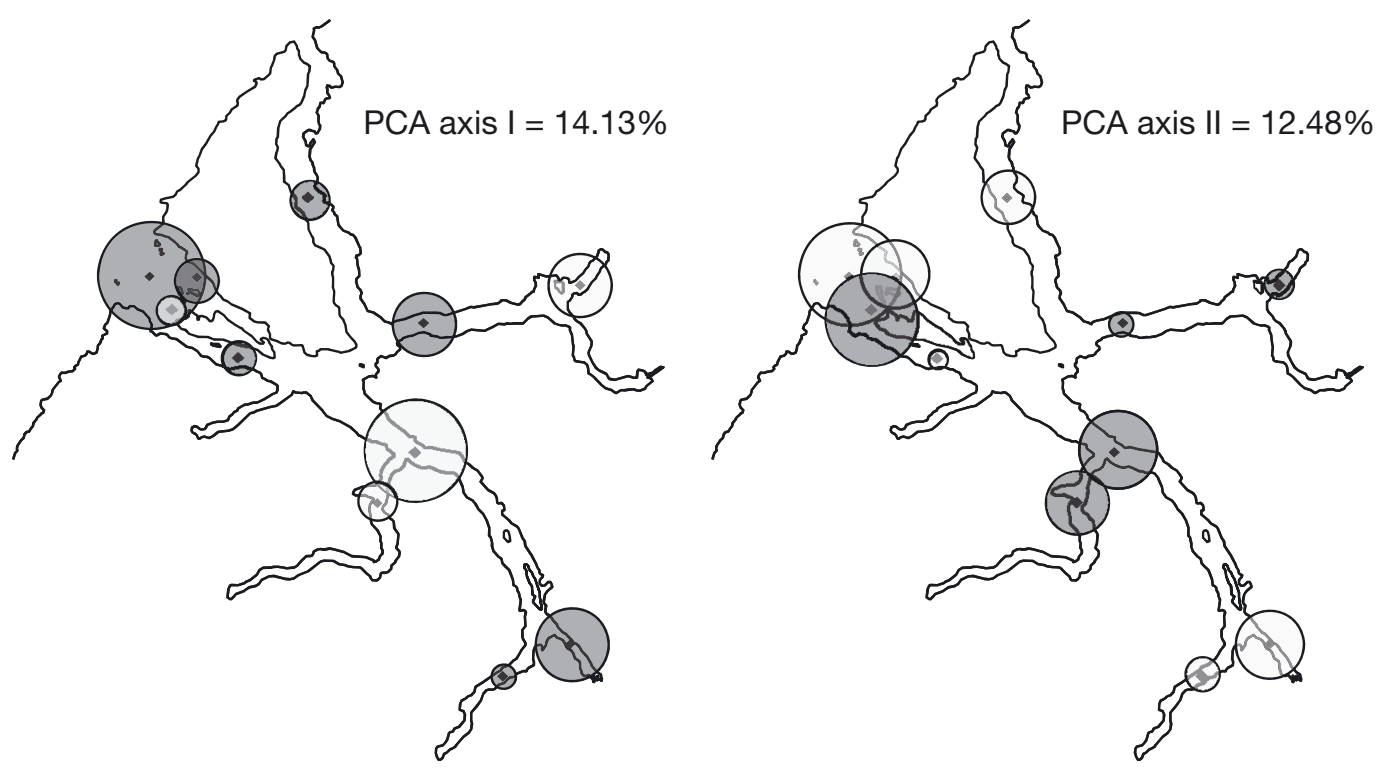

Fig. 5. Results of principal component analysis (PCA) of the partial redundancy analysis residual community matrix (unexplained, fraction U). Shown are the mean site scores for PCA axis I and axis II. Dark bubbles are negative values; clear bubbles are positive values. Relative area of bubble should be observed within each plot, but not between plots. Diamonds indicate basin sites, see Fig. 1 
object (basin) score centroids of PCA 1 and 2 are plotted on a map of Doubtful Sound in Fig. 5. The largest residual variation was found in basins along the main Doubtful Sound axis (Deep, Kellard, and entrance basins), compared to lower residual variation along the Bradshaw-Thompson Basin axis. Within each axis of the Doubtful Sound Complex, residuals varied between positive and negative variation, suggesting that factors unaccounted for in this study may not be related to along-fjord gradients, but more likely at the basin or within-basin spatial scales.

\section{DISCUSSION}

The deep basin habitats of Doubtful Sound can be placed along a number of gradients that vary over multiple spatial and temporal scales. Direct gradient analysis showed that physical and biological processes that vary across sample, basin and fjord spatial scales all made significant contributions towards explaining spatial variations of taxa variety and distribution (identified to family level, Brewin et al. 2008). Canonical ordination showed the relationships between community patterns constrained by biological and environmental factors in physical space. However, because we removed the effect of distance along the fjord (physical space) by detrending environmental factors, we determined species distributions in realised niche space (sensu Hutchinson 1957, Pielou 1975, Begon et al. 1990), i.e. the position of a taxon along a continuous gradient of pure environmental factors. Therefore, we explained $36 \%$ of the canonical variation of community distribution in realised niche space. Comparing our results to previously presented hypotheses explaining fjord benthic community pattern by BuhlMortensen and co-workers (see Introduction), all 4 hypotheses may be invoked here: (1) distance to species pool, (2) the barrier hypothesis of limited dispersal due to sills, (3) nutritional quality of sediments and (4) high \% carbon as an indication of physiological stress. In addition to these, we found that biotic interactions between individuals mediated by predators, and variability in reduced oxygen or anoxic conditions in the water column also drove benthic community patterns in Doubtful Sound.

Data presented here support the notion of multiscale control of local species abundance and distribution, as may be the case for marine environments in general (Legendre et al. 1997), where the partitioned basin-scale processes explained more variation than sample-scale processes, and fjord-scale processes explained the least amount of variation. In addition, processes are not necessarily mutually exclusive. Indeed, sources of variation can be hidden (e.g. John- son \& Goedkoop 2002) or confounded (e.g. Ohmann $\&$ Spies 1998) by correlations (inter-dependence) between environmental factors. Partitioning of variation showed that sample- and basin-scale factors were correlated; the shared explained variance accounted for $8 \%$ (fraction SB, Fig. 2) of the variation in the community structure. The correlations between basin- and fjord-scale factors (fraction BF), and sample- and fjordscale factors (fraction SF) were low, suggesting that fjord-scale factors (CONN) were reasonably independent of processes at small and local scales and not confounded by them.

Basin-scale processes of disturbance (potential for anoxia, terrestrial slips), recolonisation (between-basin connectivity), and local productivity (variability in surface stratification) explained the largest proportion of variation in benthic community structure, both collectively and on a per-variable basis. This suggests that they may be the dominant processes maintaining community structure and composition throughout the Doubtful Sound complex, particularly among the deepest, medium diversity basins (Thompson, Bradshaw, Utah, Kellard). However, these mechanisms need further elucidation. For example, processes promoting or preventing anoxia are likely to be correlated with processes of water restriction, nutrient input and flux, and productivity (Timothy \& Soon 2001). Results here showed that SILL, BC and SI (our predictor of local productivity) were poorly correlated (Fig. 4). This supports the notion that although they operate across similar spatial scales, they are likely to vary across different temporal scales. However, highly structured surface layers may enhance the risk of basin anoxia if stratification over the sill is great enough to inhibit water exchange between basins and, at the same time, have an effect on between-basin connectivity of benthic communities. It may be that our proxies reflect real-world independence between these processes in a general sense, but at certain times they have combined effects that are not reflected well by our analyses.

Spatial variability in productivity was proxied by measuring the variation in SI. However, productivity encompasses a number of other physical variables that may confound SI. Goebel et al. (2005) showed that phytoplankton concentration was, on average, highest towards the entrance of Doubtful Sound; in the present study, results for SI suggested a similar pattern. However, SI as a proxy for productivity may at best only partially explain local variation in productivity, as it does not account for variability in heterotrophic processes in the water column, nor does it balance inward or outward advection processes of the basin water column. Finally, it should be noted that SI, as well as other measurements derived from CTD data $(\mathrm{BC}, \mathrm{CONN})$, were based on less than monthly CTD data (Table 2). 
Surface oceanography can change dramatically over the course of hours in Doubtful Sound (Gibbs et al. 2000). Therefore, our estimates of surface variability may be conservative compared to natural variability. This is likely to be the case for those basins with the fewest measurements (entrance basins). However, deeper measurements are likely to have better captured variability, particularly in inner fjord basins where higher numbers of measurements were taken.

Within basins at the sample spatial scale, processes estimated here accounted for $11 \%$ of the canonical variation in community variation throughout Doubtful Sound. This combination of biotic and abiotic interactions may maintain the observed patchy nature of basin biotic (Brewin et al. 2008) and abiotic (this study) landscapes. At these scales, sporadic falls of terrestrial material (leaves, branches, logs or whole trees), which are nutritionally refractory for most macrobenthos, may have deleterious effects on the benthos due to microbial degradation creating anoxic patches. Inner basin sediments generally had high total carbon similar to that of boreal fjord systems (Burrell 1988), but greater than those reported by Syvitski et al. (1989), Buhl-Mortensen (1996) and Buhl-Mortensen \& Høisæter (1993) for sub-Arctic fjords. Brewin et al. (2008) reported a gradient of medium- (Thompson, Bradshaw, Utah and Kellard Basins) to low-diversity (Precipice, Crooked, Hall and Deep Basins) communities, which parallels the gradient in increasing sedimentary $\mathrm{C}$ and decreasing sediment nutritional quality $(\mathrm{CN})$ reported here. Although our method of sediment sample collection may have blurred sediment quality data (having homogenised surface and deeper sediments), this high refractory carbon gradient was reinforced by the presence of unique members of those communities harboring chemoautotrophic bacteria (Brewin et al. 2008). Indeed, such carbon inputs are likely to be vital in supporting the wider basin food web (McLeod \& Wing 2007). Furthermore, species such as Echinocardium cordatum (a burrowing echinoid; Brewin et al. 2008) may be key species in these high carbon communities, increasing sediment turnover and reducing anoxia in sediments (Osinga et al. 1995).

The proportion of predators was used here to proxy the potential effects of predators. If we assume that similar to the deep sea, food for detritivores is limited, predators may decrease detritivore densities, leading to reduced competitive exclusion of rare species by dominant species, and result in increased diversity (Dayton \& Hessler 1972, Grant 2000). The generally poor nutritional quality of sediments shown here, and generally low densities of taxa found throughout Doubtful Sound (Brewin et al. 2008), support this assumption. However, the effect of predators is not clear among deep-sea soft-sediment habitats, and it is possible that predators decrease diversity, similar to shallow habitats (Grant 2000). In Doubtful Sound, communities with the highest proportions of predators were concurrent with high diversity (Brewin et al. 2008) and low nutritional quality of sediments, suggesting that a positive effect on diversity due to reduced competitive exclusion is plausible. In addition to predators sampled here, there may be an additional effect of predation by epibenthic megafauna and/or demersal fish. Brewin (2003) presented 103 still images of the fjord benthos (images available on CD-ROM), showing occasional fish (possibly Macrouridae), and large gastropods (indicated by trails in the sediment) that may feed on polychaete palps, bivalve siphons or whole organisms (McLellan 1977, Wilson 1991). However, images suggest their densities are likely to be very low, and the overall effect of such predation on diversity of soft-sediment communities remains unclear (Wilson 1991). A closer examination of trophic interactions at the species level and throughout the wider food chain would benefit further comparisons between small-scale patterns in deep and shallow fjord habitats.

The contemporary fjord-wide processes of connectivity to the open ocean (i.e. regional species pool) may play a small role in maintaining community structure in the basin of Doubtful Sound. Doubtful Sound has been considered a semi-closed system, based on studies of population dynamics and genetic structure of a subtidal species (Mladenov et al. 1997, Lamare \& Stewart 1998, Wing et al. 2003, Perrin et al. 2004). Data presented here support the notion that larval exchange between the fjord and the open ocean is restricted, where a gradient of high to low CONN was demonstrated from outer to inner fjord basins (remembering that effect of distance was removed; Fig. 4). In New Zealand fjords, so called 'deep-water emergent' species have been reported, whereby some taxa that are more characteristic of deep-sea habitats have been found in shallower fjord habitats (e.g. Brewin et al. 2008); this may be explained by the deepest basins (Thompson, Bradshaw, Utah, Kellard) being better connected to the open ocean larval source than inner fjord basins. Interestingly, at the end of this study a record moment magnitude scale $\left(\mathrm{M}_{\mathrm{W}}\right) 7.2$ earthquake occurred about $10 \mathrm{~km}$ offshore of Doubtful Sound (21 August $2003,45.14^{\circ} \mathrm{S}, 166.90^{\circ} \mathrm{E}$ ), causing major landslide damage to large areas throughout the entire Doubtful Sound complex (Reyners et al. 2003), and likely having a catastrophic impact on wide areas of deep benthic habitat. After such events, fjord communities are likely to be re-established from ridge and platform systems to the north and south of the region, and the deep Tasman Sea to the west, similar to when New Zealand fjord communities were first established 
(Fleming 1950, Dell 1956, Knox 1980, Pickrill 1987, Smith 2001), and similar to historical and contemporary processes of fjords globally (e.g. Hromic et al. 2006). Thus, fjord-wide connectivity to the regional species pool may be an essential process in long-term maintenance of fjord deep benthic communities, particularly after local extinction events.

Examination of the large residual variation in community structure $(63.8 \%)$ suggests that further elucidation of physical and biological variables is needed to separate co-varying effects of variables measured here, and that other spatially structured variables have not been accounted for in this study. A high residual fraction is thought to be a common feature of ecological data (Ter Braak \& Prentice 1988) because of the patchy nature of species distributions at small spatial scales. Data show a seemingly random distribution of positive and negative departures from the partial-RDA model at the basin scale (Fig. 5). This lack of fjord-wide spatial structure suggests that there is no obvious fjord-wide residual effect, and that future studies should focus on basin-scale effects. Unexplained variation may have various sources, from small-scale stochastic processes, to unpredictable effects of historical events (Githaiga-Mwicigi et al. 2002). Also, the ability to detect large-scale effects may depend on the scale of sampling (Karlson \& Cornell 2002), or variables may be related at different spatial scales. Patterns presented in this study are interpreted mainly with respect to their spatial manifestation; there may be strong temporal variation (e.g. seasonal, annual, decadal) of physical processes that was not accounted for in this study, such as regional atmospheric and oceanographic forcings driving deep-basin water turnover (Arneborg et al. 2004). In addition, processes facilitating recruitment into and/or within the fjord necessarily must be synchronous with reproductive mode and timing. Life history strategy is particularly important when considering re-colonisation of habitats after disturbance. Species may be fast growing, or disperse widely, and are therefore good colonisers of disturbed habitats, while others colonise later and eventually outcompete original colonisers (Levin et al. 2001). Defining the dispersal potential of component species (e.g. Carson \& Hentschel 2006) would be useful for elucidating processes driving dispersal/colonisation across appropriate spatial and temporal scales (Kinlan \& Gaines 2003).

Our results suggest that community-structuring processes occur primarily at the scale of the community (assumed here to be the within-basin community). However, these processes are correlated to samplescale processes measured in the study. In this respect, the spatial and temporal scales of community maintenance in Doubtful Sound suggest that the fjords can be considered to be 'ecotone' habitats (sensu Gosz 1993) showing properties of both deep-sea and shallow softsediment systems, but also having unique properties of their own. It has been suggested that New Zealand's fjords, and fjords in general, exhibit many deep-sea like biological (reviewed by Brewin et al. 2008) and physical properties (Pickrill 1987, Syvitski et al. 1987, Burrell 1988). However, the difficulty in comparing deep-sea and shallow soft-sediment habitats is primarily in determining the boundaries of deep-sea spatial and temporal processes (Levin et al. 2001), whereas in shallow habitats, spatial and temporal boundaries are more discrete. Fjords have been described as 'ideal natural laboratories' (Syvitski et al. 1989) for such studies of effects of ecological gradients and effects of spatial scales on fjord communities due to their apparent spatially constrained, strong horizontal and vertical gradients across multiple spatial scales, and we support that notion.

In addition to small and local processes, we have shown that fjord-wide processes of connectivity to the open ocean also play a significant role in local community maintenance. Process gradients may not necessarily represent a continuum of change along a transect (physical space), but rather follow an 'abstract dimension of ecological space' (Austin 1985). In Doubtful Sound, we show spatial discontinuities in realised niche space (remembering that environmental factors were detrended with respect to distance), while basin communities are also discontinuous in physical space. The existence of such discontinuities suggests that a fjord-wide mechanism of connectivity may play an important role in local community maintenance, particularly when there is a high probability of local extinction (e.g. by way of disturbance by slips or anoxia). Thus, despite its relatively low explanatory power in numerical terms, this analysis may significantly underestimate the importance of connectivity to the regional species pool in fjord habitats. Examination of these phenomena among other fjords might further elucidate the importance of large-scale dispersal processes, and how they are dynamically linked to smaller-scale biotic and abiotic patterns and processes (Leibold et al. 2004, Cottenie 2005, Guichard \& Steenweg 2008) within the marine metacommunity of New Zealand fjords.

Acknowledgements. We acknowledge the support of staff and students of the University of Otago Department of Marine Science, including staff of the Portobello Marine Laboratory and the crew of RV 'Munida'. Special thanks also to P. Legendre for statistical advice, and F. Smith for helpful discussions throughout this study. Early versions of this manuscript benefited greatly from the comments of 3 anonymous reviewers. This study was financially supported by Meridian Energy Ltd, B. Marshall (Museum of New Zealand Te Papa Tongarewa) and a University of Otago Postgraduate Scholarship to P.E.B. 


\section{LITERATURE CITED}

Anderson MJ, Gribble NA (1998) Partitioning the variation among spatial, temporal and environmental components in a multivariate data set. Aust J Ecol 23:158-167

Angel HH, Angel MV (1967) Distribution pattern analysis in a marine benthic community. Helgol Wiss Meeresunters 15: 445-459

Ardisson PL, Bourget E (1992) Large-scale ecological patterns: discontinuous distribution of marine benthic epifauna. Mar Ecol Prog Ser 83:15-34

- Arneborg L, Erlandsson CP, Liljebladh B, Stigebrandt A (2004) The rate of inflow and mixing during deep-water renewal in a sill fjord. Limnol Oceanogr 49:768-777

Aure J, Stigebrandt A (1989) On the influence of topographic factors upon oxygen consumption rate in sill basins of fjords. Estuar Coast Shelf Sci 28:59-69

Austin MP (1985) Continuum concepts, ordination methods, and niche theory. Annu Rev Ecol Syst 16:39-61

Begon M, Harper JL, Townsend CR (1990) Ecology: individuals, populations, and communities. Blackwell Scientific, Oxford

- Berkenbusch K, Rowden AA, Probert PK (2000) Temporal and spatial variation in macrofauna community composition imposed by ghost shrimp Callianassa filholi bioturbation. Mar Ecol Prog Ser 192:249-257

Borcard D, Legendre P (1994) Environmental control and spatial structure in ecological communities: an example using oribated mites ( Acari, Oribatei). Environ Ecol Stat 1: 37-53

> Borcard D, Legendre P, Drapeau P (1992) Partialling out the spatial component of ecological variation. Ecology 73 : 1045-1055

Brewin PE (2003) Local and fjord-wide patterns of benthic community structure in the deep-basins of Doubtful Sound, Fiordland, New Zealand. PhD thesis, University of Otago, Dunedin

Brewin PE, Probert PK, Barker MF (2008) Deep-basin macrobenthos of Doubtful Sound, Fiordland, New Zealand. NZ J Mar Freshw Res 42:1-21

Buckling A, Kassen R, Bell G, Rainey PB (2000) Disturbance and diversity in experimental microcosms. Nature 408: 961-964

Buhl-Jensen L (1986) The benthic amphipod fauna of the west-Norwegian continental shelf compared with the fauna of five adjacent fjords. Sarsia 71:193-208

- Buhl-Jensen L, Fosså JH (1991) Hyperbenthic crustacean fauna of the Gullmarfjord area (western Sweden): species richness, seasonal variation and long term changes. Mar Biol 109:245-258

Buhl-Mortensen L (1996) Amphipod fauna along an offshorefjord gradient. J Nat Hist 30:23-49

> Buhl-Mortensen L, Høisæter T (1993) Mollusc fauna along an offshore-fjord gradient. Mar Ecol Prog Ser 97:209-224

Burrell DC (1988) Carbon flow in fjords. Oceanogr Mar Biol Annu Rev 26:143-226

> Carson HS, Hentschel BT (2006) Estimating the dispersal potential of polychaete species in the Southern California Bight: implications for designing marine reserves. Mar Ecol Prog Ser 316:105-113

- Chapman MG, Underwood AJ (2008) Scales of variation of gastropod densities over multiple spatial scales: comparison of common and rare species. Mar Ecol Prog Ser 354: $147-160$

$>$ Coco G, Thrush SF, Green MO, Hewitt JE (2006) Feedbacks between bivalve density, flow, and suspended sediment concentration on patch stable states. Ecology 87: 2862-2870
Cottenie K (2005) Integrating environmental and spatial processes in ecological community dynamics. Ecol Lett 8: $1175-1182$

> Dauwe B, Herman PMJ, Heip CHR (1998) Community structure and bioturbation potential of macrofauna at four North Sea stations with contrasting food supply. Mar Ecol Prog Ser 173:67-83

Dayton PK, Hessler RR (1972) Role of biological disturbance in maintaining diversity in the deep sea. Deep-Sea Res 19: 199-208

Dell RK (1956) A revision of the recent scaphopod Mollusca of New Zealand. Trans R Soc N Z 84:561-576

Diaz RJ, Rosenberg R (1995) Marine benthic hypoxia: a review of its ecological effects and the behavioural responses of benthic macrofauna. Oceanogr Mar Biol Annu Rev 33:245-303

Edgar GJ, Barrett NS (2002) Benthic macrofauna in Tasmanian estuaries: scales of distribution and relationships with environmental variables. J Exp Mar Biol Ecol 270:1-24

Etter RJ, Grassle JF (1992) Patterns of species diversity in the deep-sea as a function of sediment particle size diversity. Nature 360:576-578

Farmer DM, Freeland HJ (1983) The physical oceanography of fjords. Prog Oceanogr 12:147-220

Fleming CA (1950) The molluscan fauna of the fiords of western Southland (a report of the New Golden Hind Expedition, 1946.). NZ J Sci Technol B 31:20-40

Gage JD, Coghill GG (1977) Studies on the dispersion patterns of Scottish sea loch benthos using contiguous core transects. In: Coull BC (ed) Ecology of marine benthos. University of South Carolina Press, Columbia, SC, p 319-337

Garza C (2008) Relating spatial scale to patterns of polychaete species diversity in coastal estuaries of the western United States. Landscape Ecol 23:107-121

> Gaston KJ (2003) The how and why of biodiversity. Nature 421:900-901

Gibbs MT, Bowman MJ, Dietrich DE (2000) Maintenance of near-surface stratification in Doubtful Sound, a New Zealand fjord. Estuar Coast Shelf Sci 51:683-704

Gillibrand PA, Turrel WR, Elliott AJ (1995) Deep-water renewal in the upper basin of Loch Sunart, a Scottish fjord. J Phys Oceanogr 25:1488-1503

Githaiga-Mwicigi JMW, Fairbanks DHK, Midgley G (2002) Hierarchical processes define spatial pattern of avian assemblages restricted and endemic to the arid Karoo, South Africa. J Biogeogr 29:1067-1087

> Glover A, Paterson G, Bett B, Gage J, Sibuet M, Sheader M, Hawkins L (2001) Patterns in polychaete abundance and diversity from the Madeira Abyssal Plain, northeast Atlantic. Deep-Sea Res I 48:217-236

Glover AG, Smith CR, Paterson GLJ, Wilson GDF, Hawkins L, Sheader M (2002) Polychaete species diversity in the central Pacific abyss: local and regional patterns, and relationships with productivity. Mar Ecol Prog Ser 240: $157-170$

> Goebel NL, Wing SR, Boyd PW (2005) A mechanism for the onset of diatom blooms in a fjord with persistent salinity stratification. Estuar Coast Shelf Sci 64:546-560

Gosz JR (1993) Ecotone hierarchies. Ecol Appl 3:369-376

Grant A (2000) Deep-sea diversity: overlooked messages from shallow-water sediments. PSZNI: Mar Ecol 21:97-112

> Gray JS (2002) Species richness of marine soft-sediments. Mar Ecol Prog Ser 244:285-297

Guichard F, Bourget E (1998) Topographic heterogeneity, hydrodynamics, and benthic community structure: a scale-dependent cascade. Mar Ecol Prog Ser 171:59-70 
Guichard F, Steenweg R (2008) Intrinsic and extrinsic causes of spatial variability across scales in a metacommunity. J Theor Biol 250:113-124

Hromic T, Ishman S, Silva N (2006) Benthic foraminiferal distributions in Chilean fjords: $47^{\circ} \mathrm{S}$ to $54^{\circ} \mathrm{S}$. Mar Micropaleontol 59:115-134

Hutchinson RE (1957) Concluding remarks. Cold Spring Harbor Symp Quant Biol 22:415-427

Irwin J, Main W (1981) Doubtful Sound bathymetry 1:25 000. New Zealand Oceanographic Institute Chart Miscellaneous Series No 55, Wellington

> Johnson RK, Goedkoop W (2002) Littoral macroinvertebrate communities: spatial scale and ecological relationships. Freshw Biol 47:1840-1854

Karlson RH, Cornell HV (2002) Species richness of coral assemblages: detecting regional influences at local spatial scales. Ecology 83:452-463

Ketchum BK (ed) (1983) Estuaries and enclosed seas, Vol 26. Elsevier, New York, NY

Kinlan BP, Gaines SD (2003) Propagule dispersal in marine and terrestrial environments: a community perspective. Ecology 84:2007-2020

Kinlan BP, Gaines SD, Lester SE (2005) Propagule dispersal and the scales of marine community process. Divers Distrib 11:139-148

Klitgaard-Kristensen D, Buhl-Mortensen L (1999) Benthic foraminifera along an offshore-fjord gradient: a comparison with amphipods and molluscs. J Nat Hist 33:317-350

Knox GA (1980) Plate tectonics and the evolution of intertidal and shallow-water benthic biotic distribution patterns of the southwest Pacific. Palaeogeogr Palaeoclimatol Palaeoecol 31:267-297

Lamare MD, Stewart BG (1998) Mass spawning by the sea urchin Evechinus chloroticus (Echinodermata: Echinoidea) in a New Zealand Fiord. Mar Biol 132:135-140

Legendre P, Gallagher ED (2001) Ecologically meaningful transformations for ordination of species data. Oecologia 129:271-280

Legendre P, Legendre L (1998) Numerical ecology, Vol 20. Elsevier, Amsterdam

Legendre P, Thrush SF, Cummings VJ, Dayton PK and others (1997) Spatial structure of bivalves in a sandflat: scale and generating processes. J Exp Mar Biol Ecol 216:99-128

> Leibold MA, Holyoak M, Mouquet N, Amarasekare P and others (2004) The metacommunity concept: a framework for multi-scale community ecology. Ecol Lett 7:601-613

Levin LA, Etter RJ, Rex MA, Gooday AJ and others (2001) Environmental influences on regional deep-sea species diversity. Annu Rev Ecol Syst 32:51-93

Levin SA (1981) Mechanisms for the generation and maintenance of diversity. In: Hiorns RW, Cooke D (eds) The mathematical theory of the dynamics of biological populations. Academic Press, London, p 173-194

- Levin SA (1992) The problem of pattern and scale in ecology. Ecology 73:1943-1967

Lewis DW, McConchie D (1994) Practical sedimentology. Chapman and Hall, New York, NY

Loreau M, Mouquet N (1999) Immigration and the maintenance of local species diversity. Am Nat 154:427-440

MacArthur RH, Levins R (1967) The limiting similarity, convergence, and divergence of coexisting species. Am Nat 101:377-385

MacArthur RH, Wilson EO (1967) The theory of island biogeography. Princeton University Press, Princeton, NJ

McCabe DJ, Gotelli NJ (2000) Effects of disturbance frequency, intensity, and area on assemblages of stream macroinvertebrates. Oecologia 124:270-279
McLellan T (1977) Feeding strategies of the macrourids. Deep-Sea Res 24:1019-1036

McLeod RJ, Wing SR (2007) Hagfish in the New Zealand fjords are supported by chemoautotrophy of the forest carbon. Ecology 88:809-816

Mladenov PV, Allibone RM, Wallis GP (1997) Genetic differentiation in the New Zealand sea urchin Evechinus chloroticus (Echinodermata: Echinoidea). NZ J Mar Freshw Res 31:261-269

Morrisey DJ, Howitt L, Underwood AJ, Stark JS (1992a) Spatial variation in soft-sediment benthos. Mar Ecol Prog Ser 81:197-204

Morrisey DJ, Underwood AJ, Howitt L, Stark JS (1992b) Temporal variation in soft-sediment benthos. J Exp Mar Biol Ecol 164:233-245

> Muylaert K, Sabbe K, Vyverman W (2000) Spatial and temporal dynamics of phytoplankton communities in a freshwater tidal estuary. Estuar Coast Shelf Sci 50:673-687

Ohmann JL, Spies TA (1998) Regional gradient analysis and spatial pattern of woody plant communities of Oregon forests. Ecol Monogr 68:151-182

Osinga R, Lewis WE, Wopereis JLM, Vriezen C, van Duyl FC (1995) Effects of the sea urchin Echinocardium cordatum on oxygen uptake and sulphate reduction in experimental benthic systems under increasing organic loading. Ophelia 41:221-236

> Parry DM, Kendall MA, Pilgrim DA, Jones MB (2003) Identification of patch structure within marine benthic landscapes using a remotely operated vehicle. J Exp Mar Biol Ecol 285-286:497-511

Parsons TR, Takahashi M, Hargrave B (1984) Biological oceanographic processes. Pergamon Press, Oxford

Peres-Neto PR, Legendre P, Dray S, Borcard D (2006) Variation partitioning of species data matrices: estimation and comparison of fractions. Ecology 87:2614-2625

> Perrin C, Wing SR, Roy MS (2004) Effects of hydrographic barriers on population genetic structure of the sea star Coscinasterias muricata (Echinodermata, Asteroidea) in the New Zealand fiords. Mol Ecol 13:2183-2195

Pickrill RA (1987) Circulation and sedimentation of suspended particulate matter in New Zealand fjords. Mar Geol 74:21-39

Pielou EC (1975) Ecological diversity. John Wiley and Sons, New York, NY

> Probert PK (1984) Disturbance, sediment stability, and trophic structure of soft-bottom communities. J Mar Res 42: 893-921

Reyners M, McGinty P, Cox S, Turnbull I and others (2003) The MW 7.2 Fiordland earthquake of August 21, 2003: background and preliminary results. Bull NZ Soc Earthquake Eng 36:233-248

> Ricklefs RE (1987) Comunity diversity: relative roles of local and regional processes. Science 235:167-171

Rosenberg R (1974) Spatial dispersion of an estuarine benthic faunal community. J Exp Mar Biol Ecol 15:69-80

Smith F (2001) Historical regulation of local species richness across a geographic region. Ecology 82:792-801

Snelgrove PVR, Smith CR (2002) A riot of species in an environmental calm: the paradox of the species-rich deep-sea floor. Oceanogr Mar Biol Annu Rev 40:311-342

Snelgrove PVR, Grassle JF, Grassle JP, Petrecca RF, Stocks KI (2001) The role of colonisation in establishing patterns of community composition and diversity in shallow-water sedimentary communities. J Mar Res 59:813-831

Sokal RR, Oden NL (1978) Spatial autocorrelation in biology 1. Methodology. Biol J Linn Soc 10:199-228

Stanton BR, Pickard GL (1981) Physical oceanography of the 
New Zealand fiords. NZ Oceanogr Inst Mem 88:3-37

Swearer SE, Shima JS, Hellberg ME, Thorrold SR and others (2002) Evidence of self-recruitment in demersal marine populations. Bull Mar Sci 70:251-271

Syvitski JPM, Burrell DC, Skei JM (1987) Fjords: processes and products. Springer Verlag, New York, NY

Syvitski JPM, Farrow GE, Atkinson RJA, Moore PG, Andrews JT (1989) Baffin Island fjord macrobenthos: bottom communities and environmental significance. Arctic 42:232-247

Ter Braak CJF, Prentice IC (1988) A theory of gradient analysis. Adv Ecol Res 18:271-317

Thrush SF (1991) Spatial pattern in soft-bottom communities. Trends Ecol Evol 6:75-79

Thrush SF, Hewitt JE, Cummings VJ, Green MO, Funnell GA, Wilkinson MR (2000) The generalities of field experiments: interactions between local and broad-scale processes. Ecology 81:399-415

Thrush SF, Hewitt JE, Herman MJ, Ysebaert T (2005) Multiscale analysis of species-environment relationships. Mar

Editorial responsibility: Lisandro Benedetti-Cecchi, Pisa, Italy
Ecol Prog Ser 302:13-26

Timothy DA, Soon MY (2001) Primary production and deepwater oxygen content of two British Columbian fjords. Mar Chem 73:37-51

Tyler PA (1995) Conditions for the existence of life at the deep-sea floor: an update. Oceanogr Mar Biol Annu Rev 33:221-244

Williams SE, Marsh H, Winter J (2002) Spatial scale, species diversity, and habitat structure: small mammals in Australian tropical rain forests. Ecology 83:1317-1329

Wilson WH (1991) Competition and predation in marine softsediment communities. Annu Rev Ecol Syst 21:221-241

> Wilson GDF (1998) Historical influences on deep-sea isopod diversity in the Atlantic Ocean. Deep-Sea Res II 45: 279-301

Wing SR, Gibbs MT, Lamare MD (2003) Reproductive sources and sinks within a sea urchin, Evechinus chloroticus, population of a New Zealand fjord. Mar Ecol Prog Ser 248: $109-123$

Submitted: February 8, 2010; Accepted: December 13, 2010 Proofs received from author(s): February 27, 2011 